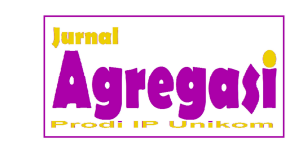

JURNAL AGREGASI

Jurnal Aksi Reformasi Government Dalam

Demokrasi

Volume 8- Nomor 1, Mei 2020

DOI: $10.34010 /$ agregasi.v8i1.2598

Available online at: https://ojs.unikom.ac.id/index.php/agregasi

\title{
IMPLEMENTASI KEBIJAKAN PEMENUHAN HAK-HAK PENYANDANG DISABILITAS BIDANG KESEJAHTERAAN SOSIAL (JAMINAN SOSIAL) DI KABUPATEN GUNUNGKIDUL TAHUN 2018
}

\author{
Adila Puspa Hestiantini' ${ }^{1)}$, Ulung Pribadi²) \\ 1,2 Program Studi Ilmu Pemerintahan, Universitas Muhammadiyah Yogyakarta, Jalan Brawijaya, \\ Geblagan, Tamantirto, Kec. Kasihan, Bantul, Daerah Istimewa Yogyakarta 55183, Indonesia. \\ E-mail: adilapuspahestya@gmail.com, Telp: +6285743294646
}

\begin{abstract}
Abstrak
Permasalahan dalam penelitian ini ialah tingkat kepuasan masyarakat penyandang disabilitas dalam menerima bantuan jaminan sosial dari pemerintah. Tujuan penelitian ini adalah untuk melihat dan menganalisis sejauh mana pemenuhan hak-hak penyandang disabilitas dalam kesejahteraan sosial berupa jaminan sosial sudah terpenuhi. Hal ini mempunyai kaitan penting dengan kebijakan pelayanan publik sebagai bentuk mensejahterakan masyarakat terutama penyandang disabilitas. Serta menganalisis keberhasilan pengimplementasian kebijakan pemenuhan hak-hak penyandnag disabilitas berupa jaminan sosial dan menganalisis secara kritis sejauhmana pengimplementasian kebijakan pemenuhan hak-hak penyandang disabilitas, sumber daya, komunikasi, sumber daya dan disposisi mempengaruhi keberhasilan kebijakan berupa jaminan sosial. Dalam variabel-variabel penelitiani ini memiliki keterhubungan yang signifikan dan tidak signifikan. Sebab, penelitian ini menggunakan pendekatan jenis peneitian kuantitatif SmartPLS dan kualitatif tanggapan wawancara (mixed methodology). Hasil penelitian menunjukan terdapat 4 variabel yang tidak signifikan dalam implementasi kebijakan pemenuhan hak penyandang disabilitas berupa jaminan sosial.
\end{abstract}

Kata kunci: Implementasi, Kebijakan, Pemenuhan Hak-Hak Penyandang Disabilitas, Kesejahteraan Sosial dan Jaminan Sosial

\section{POLICY IMPLEMENTATION TO FULFILL THE RIGHTS OF PERSONS WITH DISABILITIES IN SOCIAL WELFARE (SOCIAL SECURITY) IN GUNUNGKIDUL REGENCY IN 2018}

\begin{abstract}
The problem in this study is the level of satisfaction of people with disabilities in receiving social security assistance from the government. The purpose of this study is to see and analyze which fulfillment of disability rights in social welfare including social security that has been fulfilled. This has an important meaning with public service policies as a form of community welfare related to disability. Supporting the implementation of policies on the fulfillment of the right of persons with disabilities including social security and analyzing comprehensively the implementation of policies on fulfilling the right of persons with disabilities, resources, resources, communication, resources, and dispositions to assist in the matter of social demand problems. In the variables of this study have a significant and not significant relationship. The reason is that this study uses the type of Smart-PLS quantitative research and qualitative interview responses (mixed methodology). The results showed that 4 variables were not significant in implementing the policy on fulfilling the right to disability that contained social security.
\end{abstract}

Keywords: Implementation, Policy, Filfillment of the Rights of Persons with Disabilities, Social Welfare and Social Security 
DOI: $10.34010 /$ agregasi.v8i1.2598

Available online at: https://ojs.unikom.ac.id/index.php/agregasi

\section{PENDAHULUAN}

Istilah Penyandang Disabilitas sebelumnya dikenal dengan istilah Penyandang Cacat. Namun perkembangan terakhir Komnas HAM dan Kementerian Sosial memandang bahwa istilah Penyandang Cacat dalam perspektif bahasa Indonesia mempunyai makna yang berkonotasi negatif dan tidak sejalan dengan prinsip utama hak asasi manusia sekaligus bertentangan dengan nilai-nilai luhur bangsa yang menjunjung tinggi harkat dan martabat manusai. Penyandang Disabilitas merupakan isu yang (seharusnya) sangat femiliar dikalangan masyarakat umum saat ini, yang mana Penyandang Disabilitas merupakan sebuah bagian dari kondisi manusia dan memiliki prevalensi (jumlah orang dalam populasi yang mengalami penyakit, gangguan atau kondisi tertentu) yang cukup tinggi (M.Syafi'ie, 2014). Pengembangan ilmu di bidang perundang-undangan dapat mendorong fungsi pembentukan peraturan perundang-undangan yang sangat diperlukan kehadirannya, oleh karena itu maka dalam negara hukum, tujuan utama dari pembentukan undangundang bukan lagi untuk menciptakan kodifikasi bagi norma-norma dan nilainilai kehidupan, akan tetapi untuk menciptakan modifikasi atau perubahan dalam kehidupan masyarakat.

$$
\text { Secara konstitusional }
$$

Penyandang Disabilitas memiliki hak yang sama untuk dapat hidup sejahtera dengan cara mendapatkan kerja dan bekerja dengan layak. Sebagaimana tercantum dalam Pasal 28A, Pasal 27 Ayat (2), Pasal 28D Ayat (2) UUD 1945 Undang - Undang Dasar 1945 telah mengamanatkan bahwa pada dasarnya setiap orang memiliki hak untuk bekerja dan mendapat imbalan dan perlakuan yang adil serta layak dalam hubungan kerja tersebut. Permasalahan yang dihadapi penyandang disabilitas di Indonesia antara lain kurangnya akses informasi tentang pentingnya melakukan rehabilitasi, kurangnya fasilitas umum yang mempermudah para penyandang disabilitas melaksanakan kegiatan sehari-hari dan kurangnya akses pekerjaan untuk Penyandang Disabilitas, Kesehatan maupun Kesejahteraan Sosial bagi Penyandang Disabilitas (Sugi, 2012). Sebagai warga negara Indonesia, kedudukan, hak, kewajiban, dan peran serta penyandang disabilitas adalah sama dengan warga negara lainnya. Bahkan UUD 1945 telah mengatur bahwa "Setiap orang mendapat kemudahan dan perlakuan khusus untuk memperoleh kesempatan dan manfaat yang sama guna mencapai persamaan dan keadilan".

Perubahan dan pembaharuan Undang-Undang mengenai Pemenuhan Hak-Hak Penyandang Disabilitas. Undang-undang Nomor 4 Tahun 1997 tentang Penyandang Cacat, kemudian disempurnakan menjadi UndangUndang Nomor 19 Tahun 2011 mengenai Corvention on the Rights of Persons with Disabilities (Konvensi Hak-hak Penyandang Disabilitas), Sampai pada sebuah pergeseran paradigma tentang Penyandang Disabilitas dalam Undang- 
DOI: $10.34010 /$ agregasi.v8i1.2598

Available online at: https://ojs.unikom.ac.id/index.php/agregasi

Undang Nomor 8 Tahun 2016 tentang Penyandang disabilitas maka kedudukan penyandang disabilitas sebagai subjek (diakui keberadaannya) yaitu manusia yang bermartabat yang memiliki hak yang sama dengan warga negara lainnya. Ditambah dengan adanya Peraturan Daerah (PERDA) Kabupaten Gunungkidul Nomor 9 Tahun 2016 tentang Penyelenggara Perlindungan Dan Pemenuhan Hak Penyandang Disabilitas dan Peraturan dari Bupati Kabupaten Gunungkidul nomor 9 tahun 2016 tentang Penyelenggaraan Perlindungan dan Pemenuhan Hak Penyandang Disabilitas. Terdapat jumlah Penduduk Penyandang Disabilitas di

\section{Daerah Istimewa Yogyakarta} (DIY), yang mana tingkat tertinggi penyandang disabilitas terdapat pada daerah di Kabupaten Gunung Kidul yang berjumlah 6.797 jiwa pada tahun 2018 . Berikut data tabel dibawah ini:

Tabel 1. Jumlah Penduduk Penyandang Disabilitas Di Daerah Istimewa Yogyakarta Tahun 2018

\begin{tabular}{|c|c|c|c|c|c|c|c|}
\hline \multirow[t]{2}{*}{ Kabupaten } & \multicolumn{6}{|c|}{2018} & \multirow[b]{2}{*}{ Total } \\
\hline & $\mathbf{F}$ & TN & TW & TM & TFM & TL & \\
\hline Kulon Progo & 256 & 141 & 183 & 390 & 88 & 80 & 3.425 \\
\hline Bantul & 400 & 225 & 364 & 464 & 136 & 258 & 5.517 \\
\hline Gunungkidul & 1438 & 835 & 306 & 1747 & 643 & 1828 & 6797 \\
\hline Sleman & 396 & 224 & 329 & 519 & 164 & 230 & 5.226 \\
\hline Kota Yogyakarta & 358 & 166 & 305 & 304 & 89 & 413 & 4.553 \\
\hline
\end{tabular}

Keterangan: $\quad \mathrm{F}=$ Tuna Fisik, $\mathrm{TN}=$ Tuna Netra, TM = Tuna Mental, TFM = Tuna Fisik dan Mental, $\mathrm{TW}=$ Tuna Wicara, $\mathrm{TL}=$ Tuna Lainnya
Dari yang terlihat pada tabel di atas, bahwa dalam Pemenuhan Hak Hak Penyandang Disabilitas tentu tidak bisa dilepaskan dari kewajiban pemerintah sebagai salah satu pemegang kekuasaan. Pemerintah memiliki kuasa untuk membuat peraturan atau kebijakan sebagai representasi pemerintah untuk mewujudkan dan melindungi hak tersebut. Kewajiban pemerintah ini tertuang dalam Pasal 28I Undang-undang Nomor 8 Tahun 2016 bahwa perlindungan, pemajuan, penegakan, dan pemenuhan hak asasi manusia adalah tanggung jawab negara, terutama pemerintah. Dalam rangka mewujudkan pembangunan nasional yang bertujuan mewujudkan masyarakat yang adil dan makmur berdasarkan Pancasila dan Undang-Undang Dasar 1945.

Namun dalam sebuah implementasi kebijakan dalam mensejahterakan dan menjamin kesejahteraan sosial untuk Penyandang Disabilitas terkadang memiliki kendala dari internal yaitu pemerintah daerah itu sendiri dan eksternal yaitu masyarakat Penyandang Disabilitas. Terlebih lagi banyak aktor yang terlibat dalam mengsukseskan kesejahteraan bagi Penyandang Disabilitas di Kabupaten Gunungkidul khususnya, kolaborasi yang baik dari pemerintah pusat ke daerah, Pemerintah Daerah Kabupaten Gunungkidul dan Forum Komunikasi Disabilitas Gunungkidul (FKDG), sangat menentukan kesejahteraan Penyandang Disabilitas (Berita Pristiwa Website Resmi Kabupaten Gunungkidul (2018)). 
JURNAL AGREGASI

Jurnal Aksi Reformasi Government Dalam

Demokrasi

Volume 8- Nomor 1, Mei 2020

DOI: $10.34010 /$ agregasi.v8i1.2598

Available online at: https://ojs.unikom.ac.id/index.php/agregasi

Jaminan Sosial yaitu merupakan skema yang melembaga untuk menjamin Penyandang Disabilitas dapat memenuhi kebutuhan dasar hidupnya yang layak dan Jaminan sosial ini diberikan kepada orang tua yang tidak mampu dan yang memiliki anak penyandang disabilitas, penyandang disabilitas berat atau orang tua yang sudah tidak bekerja dan tidak mampu karena mengurus anaknya dengan penyandang disabilitas dan jaminan yang dimaksud disesuaikan dengan kemampuan keuangan daerah. (Peraturan Daerah dan Peraturan Bupati Kabuparen Gunungkidul No 8 Tahun 2016).

\section{METODE}

\section{Jenis Penelitian}

Penelitian ini menggunakan Mixed Methods Research. Mixed Methods Research adalah suatu desain penelitian yang didasari asumsi seperti metode inkuiri. Metode ini memberikan asumsi bahwa dalam menunjukkan arah atau memberi petunjuk tentang cara pengumpulan dan mengalisis data serta perpaduan pendekatan kuantitatif dan kualitatif melalui beberapa fase proses penelitian. Mixed Methods Research berfokus pada pengumpulan dan analisis daya serta memadukan antara data kuantitaif dan kualitatif (Creswell, J. W 2010:50). Data kuantitatif dalam penelitian ini menggunakan Smart-PLS.

\section{Waktu dan Lokasi Penelitian}

Penelitian ini dilakukan pada Agustus - November 2019. Adapun lokasi dari penelitian ini yaitu di Kantor Dinas Sosial Kabupaten Gunungkidul Jalan KH. Agus Salim No. 125, Wonosari, Kepek, Wonosari, Ledoksari, Kepek, Wonosari, Kabupaten Gunungkidul, Daerah Istimewa Yogyakarta, BAPEL Jamkesos DIY jalan Prof. DR. Sardjito No.5, Cokrodiningratan, Kec. Jetis, Kota Yogyakarta, Daerah Istimewa Yogyakarta 55233, KANTOR PENDAMPING PKH kec Patuk Kab. Gunungkidul

\section{Target/Subjek Penelitian}

Wawancara mendalam (in depth interview). Wawancara merupakan sumber dari data primer yang sesuai dengan kebutuhan analisis. Wawancara yang dilakukan kepada stekholders dengan melakukan tanya jawab atau memberikan sejumlah pertanyaan kepada narasumber yang berkompeten di bidangnya sesuai dengan indikatorindikator pada penelitian ini. Wawancara dilakukan dengan secara lisan dan tatap muka. Adapun pihak-pihak yang menjadi informan dalam penelitian ini adalah: 
DOI: $10.34010 /$ agregasi.v8i1.2598

Available online at: https://ojs.unikom.ac.id/index.php/agregasi

Tabel 2. Sasaran Narasumber

\begin{tabular}{|c|l|}
\hline No & \multicolumn{2}{|c|}{ Jabatan } \\
\hline 1 & $\begin{array}{l}\text { Sekretaris Dinas Sosial } \\
\text { Daerah Kabupaten } \\
\text { Gunungkidul }\end{array}$ \\
\hline 2 & $\begin{array}{l}\text { Kepala Seksi Kesejahteraan } \\
\text { Sosial Kabupaten } \\
\text { Gunungkidul }\end{array}$ \\
\hline 4 & $\begin{array}{l}\text { Operator Program Keluarga } \\
\text { Harapan (PKH) Dinas Sosial } \\
\text { Kab Gunungkidul }\end{array}$ \\
\hline 5 & $\begin{array}{l}\text { Pendamping Program PKH } \\
\text { Kecamatan Patuk }\end{array}$ \\
\hline 6 & $\begin{array}{l}\text { Forum Komunikasi } \\
\text { Disabilitas Gunungkidul } \\
\text { (FKDG) }\end{array}$ \\
\hline 7 & Penyandang Disabilitas Berat \\
\hline 8 & BAPEL DIY \\
\hline
\end{tabular}

Serta data dokumentasi berupa Arsip Dokumentasi Dinas Sosial Kab. Gunungkidul dan LSM, Laporan Kegiatan Jaminan Sosial, Struktur Birokrasi, Peraturan Perundang-undangan, Buku Literasi. Dan survey Survey merupakan salah satu metode penelitian sosial yang sangat luas penggunaannya. Penelitian ini memiliki ciri khas yang ditunjukkan dari jumlah sampel cukup besar, dan cara pengumpulan datanya yang dilakukan dengan menggunakan perangkat kuesioner (Wirawan, 2011: 41). Kuesioner merupakan daftar pernyataan atau pertanyaan yang dikirimkan kepada responden baik secara langsung atau tidak langsung (melalui pos atau perantara) (Usman, 2008: 51). Daftar pertanyaan dalam penelitian ini diajukan dengan jawaban tertutup, yaitu sudah disediakan jawabannya sehingga responden hanya perlu memilih jawaban yang telah disediakan dan memberi tanda pada jawaban yang menurut mereka sesuai dengan pendapatnya. Kuesioner dalam penelitian ini diberikan kepada masyarakat Penyandang Disabilitas Kabupaten Gunungkidul dilihat dari jumlah Penyandang Disabilitas.

Tabel 3. Penilaian Skor Pertanyaan

\begin{tabular}{|c|c|}
\hline Jenis Jawaban & Skor \\
\hline Sangat $\quad$ Tidak & 1 \\
\hline Setuju (STS) & 2 \\
\hline Tidak Setuju (TS) & 3 \\
\hline Netral $(\mathrm{N})$ & 4 \\
\hline Setuju (S) & 5 \\
\hline Sangat Setuju (SS) & \\
\hline
\end{tabular}

Teknik pengambilan populasi pada penelitian ini Semua variabel dipertimbangkan dalam penelitian ini, dioperasionalkan dengan indikator masing-masing yang digunakan sebagai basis dalam membuat kuesioner dan paduan wawancara. Data primer dikumpulkan dengan menggunakan survei cross-sectional yang dilakukan di antara Dinas Sosial, Bapel, FKDG, PKH yang menjalankan pelayanan berupa jaminan sosial kepada penyandang disabilitas berat di Kabupaten Gunungkidul.

Nursalam, (2013) cross sectional, dimana penelitian dipertimbangkan dengan pengukuran waktu atau pengamatan terhadap data dependen dan variabel dependen satu kali pada 
JURNAL AGREGASI

Jurnal Aksi Reformasi Government Dalam

Demokrasi

Volume 8- Nomor 1, Mei 2020

DOI: $10.34010 /$ agregasi.v8i1.2598

Available online at: https://ojs.unikom.ac.id/index.php/agregasi

waktu tertentu. Setiap variabel ditentukan pada suatu waktu, maka prevalensi dan efek dari suatu fenomena akan diperoleh yang kemudian diselesaikan oleh faktor-faktor penyebabnya. Jumlah Penyandang Disabilitas di Kabupaten Gunungkidul di 18 Kecamatan yaitu 6797.

Sedangkan pengambilan sempel cara pengumpulan data yang hanya mengambil sebagian elemen populasi atau karakeristik yang ada dalam populasi (Hasan, 2015: 85). Teknik sampling yang digunakan dalam penelitian ini adalah cluster proportional random sampling. Kabupaten Gunungkidul terdiri dari 18 Kecamatan. Setelah ditentukan populasinya, dalam menentukan besarnya sampel menggunakan rumus Slovin. Cara menentukan jumlah sampel menggunakan rumus Slovin adalah sebagai berikut (Noor, 2011: 158):

$$
n=\frac{N}{1+N e^{2}}
$$

Keterangan:

$n=$ Jumlah sampel

$\mathrm{N}=$ Anggota populasi, dalam penelitian ini populasinya adalah masyarakat di Kabupaten Gunungkidul

$\mathrm{e}=$ Tingkat kesalahan $10 \%(0,1)$ dengan tingkat kepercayaan $90 \%$ berdasarkan rumus di atas maka dapat dihitung sampel dalam penelitian,sebagai berikut:

$$
n=\frac{6.797}{1+6.797(0,1)^{2}}
$$

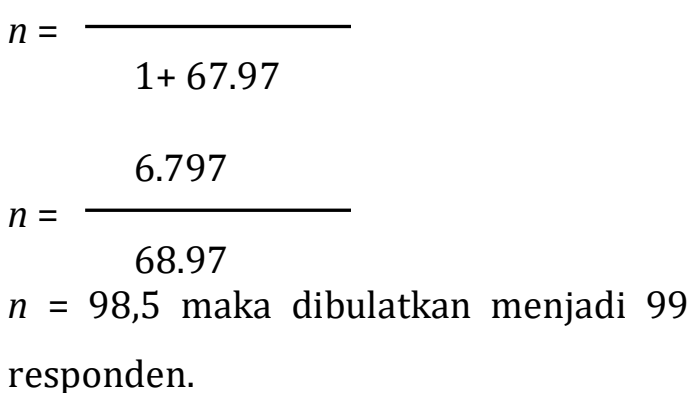

Setelah diketahui jumlah sampel dari populasi, selanjutnya jumlah sampel tersebut dibagi secara proporsional ke dalam setiap kelompok sampel. Pembagian kelompok sampel penelitian ini berdasarkan pada jumlah penyandang disabilitas berat di Kabupaten Gunungkidul, yang menggunakan random sampling ke 99 responden penyandang disabilitas berat di Kabupaten Gunungkidul.

\section{Teknik Analisis Data}

Setelah dilakukan pengelompokan dan reduksi data, maka baik data kualitatif (hasil wawancara) maupun data kuantitatif (hasil kuisioner) dilakukan analisis datanya dengan cara sebagai berikut:

1) Analisis Data Wawancara

Hasil wawancara dianalisis guna mengukur sejauh mana pengimplementasian pemenuhan hakhak penyandang disabilitas pada jaminan sosial di Kab. Gunungkidul. Hasil wawancara ini dianalisis dengan cara melakukan kroscek hasil wawancara terhadap indikator-indikator dalam pengimplementasian pemenuhan hakhak penyandang disabilitas pada 
DOI: $10.34010 /$ agregasi.v8i1.2598

Available online at: https://ojs.unikom.ac.id/index.php/agregasi

jaminan sosial di Kab. Gunungkidul.

2) Analisis Data Kuesioner

Pada penelitian ini data kuesioner dianalisis menggunakan ini menggunakan Analisis Partial Least Squares (PLS) dengan alat bantu berupa program Smart-PLS 3.0. Menurut Hartono dan Abdillah (2015:161) PLS adalah salah satu metode alternative statistik Structural Equation Modelling (SEM) berbasis varian yang didesain untuk menyelesaikan regresi berganda ketika terjadi permasalahan spesifik pada data, seperti ukuran sampel penelitian kecil, adanya data yang hilang (missing values) dan multikolenieritas.

Analisis PLS terdiri dari dua sub model yaitu model pengukuran atau outer model dan model struktural atau inner model (Ghozali dan Hengky, 2014:7). Model pengukuran digunakan untuk uji validitas dan realibilitas, sedangkan model struktural digunakan untuk uji kausalitas. PLS dapat mengukur data dengan skala berbeda secara bersamaan. PLS dapat dijalankan pada data set berukuran kecil, yaitu sepuluh kali skala dengan jumlah terbesar dari indikator yang bersifat formatif atau sepuluh kali jumlah path (jalur) yang menunjukan hubungan kausalitas antar konstruk laten.

Inner Model, yaitu spesifikasi hubungan antar variabel laten (structural model), disebut juga dengan inner relation, menggambarkan hubungan antar variabel laten berdasarkan teori substansif penelitian. Tanpa kehilangan sifat umumnya, diasumsikan bahwa variabel laten dan indikator atau variabel manifest diskala zero means dan unit varian sama dengan satu, sehingga parameter lokasi (parameter konstanta) dapat dihilangkan dari model. Model persamaannya dapat ditulis seperti di bawah ini:

\section{$\eta=\beta \eta+\Gamma \xi+\varsigma$}

Dimana menggambarkan vektor variabel endogen (dependen), adalah vektor variabel laten eksogen dan adalah vektor residual (unexplained variance). Oleh karena PLS didesain untuk model rekursif, maka hubungan antar variabel laten, berlaku bahwa setiap variabel laten dependen, atau sering disebut causal chain system dari variabel laten dapat dispesifikasikan sebagai berikut:

\section{$\eta \mathbf{j}=\Sigma \mathbf{i} \beta \mathbf{j i} i \mathbf{i}+\boldsymbol{\Sigma} \mathbf{i} \gamma \mathbf{j b} \xi \mathbf{b}+\boldsymbol{c j}$}

Dimana $\gamma \mathrm{jb}$ (dalam bentuk matriks dilambangkan dengan $\Gamma$ ) adalah koefisien jalur yang menghubungkan variabel laten endogen $(\eta)$ dengan eksogen ( $)$ ). Sedangkan $\beta$ ji (dalam bentuk matriks dilambangkan dengan $\beta$ ) adalah koefisien jalur yang menghubungkan variabel laten endogen ( $\eta$ ) dengan endogen ( $\eta$ ); untuk range indeks i dan b. Parameter $\varsigma$ j adalah variabel inner residual.

Outer model, yaitu spesifikasi hubungan antara variabel laten dengan indikatornya, disebut juga dengan outer relation atau 
measurement model, mendefinisikan karakteristik konstruk dengan variabel manifesnya. Model indikator refleksif dapat ditulis persamaannya sebagai berikut:

$$
\begin{aligned}
& x=\Lambda x \xi+\delta \\
& y=\Lambda y \eta+\varepsilon
\end{aligned}
$$

Di mana $\mathrm{x}$ dan y adalah indikator untuk variabel laten eksogen $(\xi)$ dan endogen ( $\eta$ ). Sedangkan $\Lambda \mathrm{x}$ dan $\Lambda \mathrm{y}$ merupakan matriks loading yang menggambarkan seperti koefisien regresi sederhana yang menghubungkan variabel laten dengan indikatornya. Residual yang diukur dengan $\delta$ dan $\varepsilon$ dapat diinterpretasikan sebagai kesalahan pengukuran atau noise. Model indikator formatif persamaannya dapat ditulis sebagai berikut:

$$
\begin{aligned}
& \xi=\Pi \xi X i+\delta \\
& \eta=\Pi \eta Y i+\varepsilon
\end{aligned}
$$

Dimana $\xi \eta \eta, X$, dan $Y$ sama dengan persamaan sebelumnya. Dengan $\Pi \xi$ dan $\Pi \eta$ adalah seperti koefisen regresi berganda dari variabel laten terhadap indikator, sedangkan $\delta$ dan $\varepsilon$ adalah residual dari regresi.

\section{HASIL DAN PEMBAHASAN}

Pada dasarnya setiap kebijakan yang dibuat oleh Pemerintah Daerah memiliki manfaat untuk membantu masyarakat terutama masyarakat Penyandang Disabilitas dalam mendapatkan hak-haknya yaitu mendapatkan pelayanan yang mereka butuhkan. Dengan demikian pemerintah daerah dituntut untuk mengimplementasikan kebijakankebijakan dalam pemenuhan hak-hak penyandang disabilitas bidang Kesejahteraan Sosial (Jaminan Sosial). Beberapa program yang telah di laksanakan oleh Dinas Sosial Kabupaten Gunungkidul yaitu Kartu JAMKESOS (Jaminan Kesehatan Sosial) dan PKH (Program Keluarga Harapan) guna membantu masyarakat penyandang disabilitas yang masih minim dalam kesejahteraan sosialnya.

\section{Implementasi Kebijakan dalam Pemenuhan Hak-Hak Penyandang Disabilitas Bidang Kesejahteraan Sosial (Jaminan Sosial)}

$$
\text { Implementasi dalam }
$$

Pemenuhan Hak-Hak Penyandang Disabilitas Bidang Kesejahteraan Sosial (Jaminan Sosial) di Kabupaten Gunungkidul memiliki 2 program yang mendukung pemenuhan hak-hak penyandang disabilitas yaitu Program Keluarga Harapan (PKH) dan JAMKESOS (Jaminan Kesehatan Sosial). Program Keluarga Harapan (PKH) adalah program perlindungan sosial yang memberikan bantuan uang tunai kepada Rumah Tangga Sangat Miskin (RTSM) dengan syarat dapat memenuhi kewajiban terkait pendidikan dan kesehatan. PKH, bertujuan mengurangi beban RTSM dan diharapkan dapat memutus mata rantai kemiskinan antargenerasi, sehingga generasi berikutnya dapat keluar dari kemiskinan. PKH juga mendukung pencapaian Tujuan 
DOI: $10.34010 /$ agregasi.v8i1.2598

Available online at: https://ojs.unikom.ac.id/index.php/agregasi

Pembangunan Millenium atau Millenium

Development Goals (MDGs) dari

Kementrian Sosial. Yang mana diiharapkan untuk masyarakat penyandang disabilitas yang membutuhkan di bantu agar hidupnya lebih sejahtera.

Dari rincian banyaknya program kerja dan kegiatan Dinas Sosial Kab. Gunungkidul, terdapat 2 program yang dilaksanakan yang berkaitan dengan pemenuhan hak-hak penyandang disabilitas, yaitu :

1. PKH (Program Keluarga Harapan) Untuk memperoleh bantuan dari Program PKH Dinas Sosial / TKSK akan mendata masyarakat yang layak untuk mendapatkan PKH terutama penyandang disabilitas yang miskin, kemudian setelah di data akan dimasukkan ke dalam Operator PKH yang terdapat di Dinsos Kabupaten Gunungkidul, setelah itu ada pendamping PKH di setiap kecamatan yang terdapat di kabupaten gunungkidul yang mengkoordinir, melaksanakan, memberi bantuan PKH tersebut langsung ke masyarakat, pada tahun 2018 menggunakan sistem komunitas, jadi komunitas itu penerima PKH di kumpulkan jadi satu kemudian diundang ke balai desa atau ke tempat yang memadai, kemudian pihak bank datang dan kmudian melakukan pencairan di tempat, kan mereka pakai kartu atm/kks (kartu keluarga sejahtera). Kemudian bisa juga homevisit setelah untuk pencairan dana $\mathrm{PKH}$ terutama untuk masyarakat penyandang disabilitas yang keterbatasan untuk hadir saat pertemuan. Pendamping PKH yang tersebar pada setiap kecamatan terdapat 200 SDM yang tersedia dan 1 kecamatan sekitar 10 SDM yang tesedia dan yang dalam kategori disabilitas yang mendapatkan PKH yaitu disabilitas berat yang tidak dapat bangun dari tempat tidur dan yang sudah tidak bisa mencari nafkah.

2. Jamkesus (Jaminan Kesehatan Khusus) jaminan berupa kesehatan sosial yang mana kartu Jamkesos dari Dinas Kesehatan DIY melalui Balai Penyelenggara Jaminan Kesehatan Sosial (BAPEL) DIY. Kartu Jamkesus bisa digunakan untuk mengakses layanan kesehatan khusus di wilayah DIY, contohnya untuk akses berobat, akses alat bantu dan terapi terapi khusus untuk penyandang disabilitas. Dinas Sosial belum mempunyai anggaran tersendiri dalam pelaksanaan pelayanan jaminan kesehatan khusus di Gunungkidul namun setiap tahun Dinas Kesehatan DIY melalui Balai Penyelenggara Jaminan Kesehatan Sosial DIY bekerjasama dengan Dinas Sosial Kabupaten Gunungkidul selaku Organisasi Perangkat Daerah yang melaksanakan pelayanan sosial dalam bidang jaminan kesehatan akan mengadakan pelayanan kesehatan untuk warga penyandang disabilitas miskin di Kabupaten 
DOI: $10.34010 /$ agregasi.v8i1.2598

Available online at: https://ojs.unikom.ac.id/index.php/agregasi

Gunungkidul. Pelaksanaan Jamkesos Terpadu pada tahun 2018 di Kodim Wonosari sasaran khusus peserta penyandang disabilitas dari Kecamatan Wonosari, Karangmojo, Semanu, Ponjong. Target peserta Pelayanan Jamkesos Terpadu pada tahun tersebut sebanyak 150 orang (terpenuhi sekitar 130-an) dengan melibatkan beberapa OPD terkait seperti Bapedda, Bagian Kesra Sekda, Organisasi Masyarakat dan untuk memaksimalkan jumlah penyandang disabilitas yang memperoleh layanan, Dinas Sosial memberikan informasi melalui FKDG yaitu Forum Komunikasi Disabilitas Gunungkidul. Untuk memperoleh bantuan dari Jamkesus pemegang kartu jamkesos yang ingin mengakses alat bantu dan perawatan kesehatan meminta rujukan dari puskesmas, surat rujukan dan kartu jamkesus di bawa pada saat dilaksanakannya jamkesos terpadu yang atau langsung dibawa ke kantor Bapel Jamkesos. Kemudian Bapel menverifikasi berkas, mengecek keadaan pasien dan kebutuhan pasien, kemudian diberikan surat SEP dari bapel untuk akses alat bantu atau perawatan kesehatan di puskesmas/RS/ yang di inginkan dan fasilitas kesehatan yang dituju.

Tabel 4. Construct Realibility dan Validaty

\begin{tabular}{|c|c|}
\hline $\begin{array}{c}\text { Cronbach's } \\
\text { Alpha }\end{array}$ & N of Items \\
\hline 0.912 & 30 \\
\hline
\end{tabular}

Berdasarkan Tabel 4 di atas, penelitian ini memiliki 99 responden dari jumlah penyandang disabilitas yang mendapatkan bantuan berupa jaminan sosial yaitu program PKH dan jamkesus. Secara praktis mewakili seluruh populasi yang diidentifikasi untuk penelitian ini. Validitas data tidak hanya bergantung pada jumlah dan karakteristik responden tetapi juga pada jenis pertanyaan yang diajukan. Saat pertanyaan untuk penelitian ini diuji, jumlah item pernyataan ada 30 dari 5 variable (Implementasi kebijakan pemenuhan hak penyandang disabilitas, Komunikasi, Sumber Daya, Disposisi, Struktur Birokrasi) dan nilai analisis Alpha Cronbach adalah 0.912. nilai ini menunukan bahwa kuesioner yang digunakan dalam mengumpulkan data primer valid dan dapat diandalkan.

\section{Indikator (The Outer Model: Validity and Reliability)}

Pengujian outer model dilakukan dengan cara mengevaluasi outer model dengan indikator refleksinya. Ada 3 kriteria yang merupakan indikator refleksinya, yaitu convergent validity, discriminant validity dan contructs validity dengan menggunakan convergent validity and discriminant validity sebagai indikatornya. 
DOI: $10.34010 /$ agregasi.v8i1.2598

Available online at: https://ojs.unikom.ac.id/index.php/agregasi

Tabel 5. Discriminant Validity - HeterotraitMonotrait Ratio of Correlations (HTMT)

\begin{tabular}{|l|l|l|l|l|l|}
\hline $\begin{array}{l}\text { Variabe } \\
\mathbf{l}\end{array}$ & $\begin{array}{l}\text { Dispo } \\
\text { sisi } \\
\text { an } \\
\text { Disabili } \\
\text { tas }\end{array}$ & $\begin{array}{l}\text { Kebijak } \\
\text { kasi }\end{array}$ & $\begin{array}{l}\text { Strukt } \\
\text { ur } \\
\text { Birokr } \\
\text { asi }\end{array}$ & $\begin{array}{l}\text { Sumb } \\
\text { er } \\
\text { Daya }\end{array}$ \\
\hline $\begin{array}{l}\text { Disposis } \\
\text { i }\end{array}$ & 0.637 & & & & \\
\hline $\begin{array}{l}\text { Kebijaka } \\
\text { n } \\
\text { Disabilit } \\
\text { as }\end{array}$ & 0.692 & 0.767 & & & \\
\hline $\begin{array}{l}\text { Komuni } \\
\text { kasi }\end{array}$ & 0.643 & 0.573 & 0.804 & & \\
\hline $\begin{array}{l}\text { Struktur } \\
\text { Birokras } \\
\text { i }\end{array}$ & 0.727 & 0.475 & 0.437 & 0.699 & \\
\hline $\begin{array}{l}\text { Sumber } \\
\text { Daya }\end{array}$ & 0.657 & 0.570 & 0.721 & 0.378 & 0.837 \\
\hline
\end{tabular}

Nilai HTMT tertinggi di antara variabel adalah 0,837. Oleh karena itu, lebih rendah dari nilai 0,85 atau 0,90 yang ditetapkan. Selain itu, temuan yang sama berlaku untuk kriteria inferensi HTMT yang didefinisikan dengan menjalankan rutin bootstrap. Rutin bootstrap menunjukkan nilai variabel di bawah interval kepercayaan dan interval bias kepercayaan dikoreksi. Semua nilai berbeda secara signifikan dari 1 . Oleh karena itu, validitas diskriminan ditetapkan untuk model luar yang digunakan dalam penelitian ini.
Tabel 6. Faktor Analisis

\begin{tabular}{|c|c|c|c|c|c|}
\hline Variabel & $\begin{array}{l}\text { Indikator- } \\
\text { indikator }\end{array}$ & $\begin{array}{l}\text { Outer } \\
\text { Loadings }\end{array}$ & $\begin{array}{l}\text { Crinbach's } \\
\text { Alpha }\end{array}$ & $\begin{array}{l}\text { Composite } \\
\text { Reliability }\end{array}$ & $\begin{array}{l}\text { Avarage } \\
\text { Variance } \\
\text { Extracted } \\
(A V E)\end{array}$ \\
\hline $\begin{array}{l}\text { Kebijakan } \\
\text { Pemenuhan } \\
\text { Hak-Hak } \\
\text { Penyandang } \\
\text { Disabilitas }\end{array}$ & Pelayanan & $\begin{array}{l}0.830 \\
0.783 \\
0.671 \\
0.869 \\
0.819 \\
0.747 \\
0.644 \\
0.775 \\
0.742 \\
0.764\end{array}$ & 0.921 & 0.934 & 0.589 \\
\hline Komunikasi & $\begin{array}{l}\text { Transforma } \\
\text { si Informasi, } \\
\text { Kejelasan } \\
\text { Informasi, } \\
\text { dsn } \\
\text { Konsisten } \\
\text { Informasi }\end{array}$ & $\begin{array}{l}0.849 \\
0.863 \\
0.852 \\
0.715 \\
0.726\end{array}$ & 0.862 & 0.901 & 0.646 \\
\hline $\begin{array}{c}\text { Sumber } \\
\text { daya }\end{array}$ & $\begin{array}{l}\text { Staff, } \\
\text { Information } \\
\text {, Authority, } \\
\text { Facilities }\end{array}$ & $\begin{array}{l}0.901 \\
0.887 \\
0.718 \\
0.828 \\
\end{array}$ & 0.854 & 0.903 & 0.700 \\
\hline Disposisi & $\begin{array}{l}\text { Perilaku } \\
\text { dan } \\
\text { Karakteristi } \\
\text { k }\end{array}$ & $\begin{array}{l}0.537 \\
0.773 \\
0.781 \\
0.710 \\
0.706 \\
0.580 \\
0.500 \\
0.735\end{array}$ & 0.822 & 0.866 & 0.453 \\
\hline $\begin{array}{l}\text { Struktur } \\
\text { Birokrasi }\end{array}$ & $\begin{array}{l}\text { SOP dan } \\
\text { Struktur } \\
\text { Birokrasi }\end{array}$ & $\begin{array}{l}0.821 \\
0.645 \\
0.615\end{array}$ & 0.564 & 0.739 & 0.489 \\
\hline
\end{tabular}

Untuk variabel kebijakan dengan indikator pelayanan memilliki nilai Crinbach's Alpha 0.921, Composite Reliability 0.934, Avarage Variance Extracted (AVE) 0.589 bahwa nilai ini valid. Berdasarkan tabel di atas bahwa untuk variabel komunikasi memilliki nilai Crinbach's Alpha 0.862, Composite Reliability 0.901, Avarage Variance Extracted (AVE) 0.646 bahwa nilai ini valid. Berdasarkan tabel di atas bahwa untuk variabel Sumber daya memilliki nilai Crinbach's Alpha 0.854, Composite Reliability 0.903, Avarage Variance Extracted (AVE) 0.700 bahwa nilai ini valid. Berdasarkan tabel di atas bahwa untuk variabel Disposisi memilliki nilai Crinbach's Alpha 0.822, Composite Reliability 0.866 , nilai ini valid sedangkan 
DOI: $10.34010 /$ agregasi.v8i1.2598

Available online at: https://ojs.unikom.ac.id/index.php/agregasi

Avarage Variance Extracted (AVE) 0.453 tidak valid. Berdasarkan tabel di atas bahwa untuk variabel Struktur Birokrasi memilliki nilai Crinbach's Alpha 0.564 nilai ini tidak valid, Composite Reliability 0.739 nilai ini valid, Avarage Variance Extracted (AVE) 0.489 nilai ini tidak valid.

Tabel 7. Penilaian Model Struktural The Inner Model: R Square, Q2, VIF, dan F2

\begin{tabular}{|l|l|l|l|}
\hline Variable & $\begin{array}{l}\text { R } \\
\text { Square }\end{array}$ & $\begin{array}{l}\text { Predictive } \\
\text { Relevance } \\
\text { (Q2) }\end{array}$ & $\begin{array}{l}\text { Collinearity } \\
\text { Statistics } \\
\text { (VIF) }\end{array}$ \\
\hline Disposisi & 0.754 & 0.169 & 1.760 \\
\hline Komunikasi & 0.328 & 0.020 & 2.336 \\
\hline $\begin{array}{l}\text { Struktur } \\
\text { Birokrasi }\end{array}$ & 0.266 & 0.623 & 1.363 \\
\hline Sumber Daya & 0.556 & 0.116 & 2.254 \\
\hline
\end{tabular}

Sebelum analisis regresi, model struktural penelitian ini dinilai menggunakan nilai-nilai R2, Q2, and Collinearity Statistics (VIF) untuk lebih memastikan bahwa model struktural valid. Terutama, nilai R2 berkisar antara 0 dan 1, tingkat yang lebih tinggi, akurasi prediksi yang lebih tinggi. Menurut Chin (1998) dan Henseler et al. (2009), nilai R2 lebih besar dari 0,840 menunjukkan akurasi prediksi yang tinggi, kisaran 0,33 - 0,67 menunjukkan efek yang dimoderasi, R2 antara 0,19 dan 0,33 menunjukkan efek rendah, sedangkan nilai R2 di bawah 0,19 dianggap tidak dapat diterima (variabel eksogen tidak dapat menjelaskan variabel dependen endogen). Sementara nilai Q2 lebih besar dari nol untuk variabel laten endogen reflektif tertentu menunjukkan relevansi prediktif model jalur untuk konstruk dependen spesifik (Hair et al. 2014).
Selain itu, multikolinieritas adalah masalah yang terjadi dengan analisis regresi ketika ada korelasi tinggi setidaknya satu variabel independen dengan kombinasi variabel independen lainnya. Dalam regresi berganda, variance inflation factor (VIF) digunakan sebagai indikator multikolinieritas. Oleh karena itu, nilai ideal VIF adalah 1.000 sementara nilai kurang dari 6 atau 10 dapat diterima dalam kondisi yang menguntungkan. Namun untuk struktur birokrasi nilai R2 tidak dapat diterima.

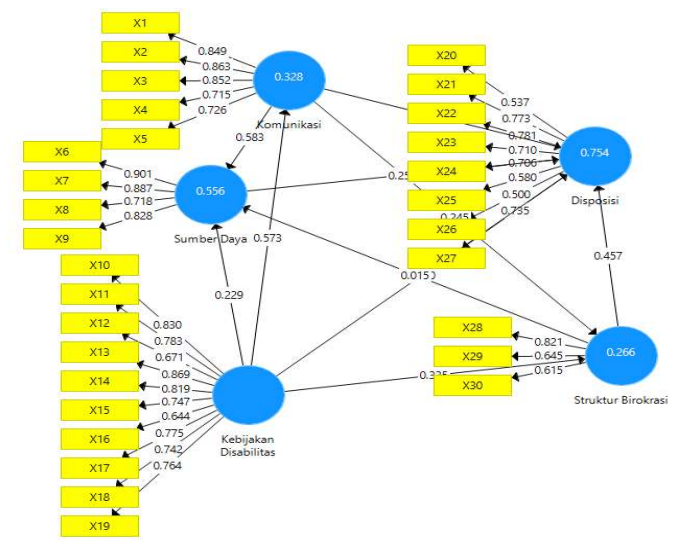

Gambar 1. Model Struktural menunjukan Model P yang sesuai

Model struktural dianggap cocok untuk penelitian ini berdasarkan hasil Analisis Fit Model (model fit). Model Fit Analysis digunakan untuk menguji apakah model tersebut sesuai dengan ukuran konstruk yang digunakan dalam penelitian ini. Dengan partial least square (PLS), model yang sesuai analisis untuk penelitian ini mempertimbangkan indikator berikut: SRMR, d_ULS, d_G dan NFI. Hasil SRMR adalah 0.123 yang lebih rendah dari 6.984 atau 18.226 dan menyiratkan bahwa model tersebut 
DOI: $10.34010 /$ agregasi.v8i1.2598

Available online at: https://ojs.unikom.ac.id/index.php/agregasi

sesuai. Terakhir, nilai untuk NFI adalah 0,916 yang lebih dekat dengan 1 dan karenanya menyiratkan kesesuaian yang lebih baik untuk model tersebut. Atas dasar tes ini, model struktural pada Gambar 1 dianggap cocok untuk penelitian ini.

Tabel 8. Model Fit Analysis

\begin{tabular}{|l|l|l|l|}
\hline Indicator & $\begin{array}{l}\text { Suggested } \\
\text { Value }\end{array}$ & $\begin{array}{c}\text { Saturated } \\
\text { Model }\end{array}$ & Assessment \\
\hline SRMR & $>0.10$ & 0.123 & $\begin{array}{l}\text { Modelnya } \\
\text { Pas (model } \\
\text { fit) }\end{array}$ \\
\hline d_ULS & $>.05$ & 6.984 & $\begin{array}{l}\text { Modelnya } \\
\text { Pas (model } \\
\text { fit) }\end{array}$ \\
\hline d_G & $>.05$ & 18.226 & $\begin{array}{l}\text { Modelnya } \\
\text { Pas (model } \\
\text { fit) }\end{array}$ \\
\hline NFI & $\begin{array}{l}\text { Kurang } \\
\text { dari atau } \\
\text { lebih ke 1 }\end{array}$ & 0.916 & $\begin{array}{l}\text { Modelnya } \\
\text { Pas (model } \\
\text { fit) }\end{array}$ \\
\hline
\end{tabular}

Test Hipotesis: Analisis Regresi (PLSSEM)

Pengujian hipotesis antar variable yaitu variable exsogen terhadap variable endogen, yang dilakukan menggunakan metode resampling bootstrap setelah mengetahui valid dan reliabelnya data. Uji statistik yang digunakan adalah statistic $\mathrm{t}$ atau uji $\mathrm{t}$. pengujian dapat dinyatakan signifikan jika dari T-Statistik nilainya $>1.96$ dan nilai dari P values < 0.05 (Haryono,2017). Pengujian hipotesis dilakukan dengan mengetahui output path coefficient dari hasil resampling.
Tabel 9. Hypotheses Testing: Summary of the Path Anlysis Evaluation

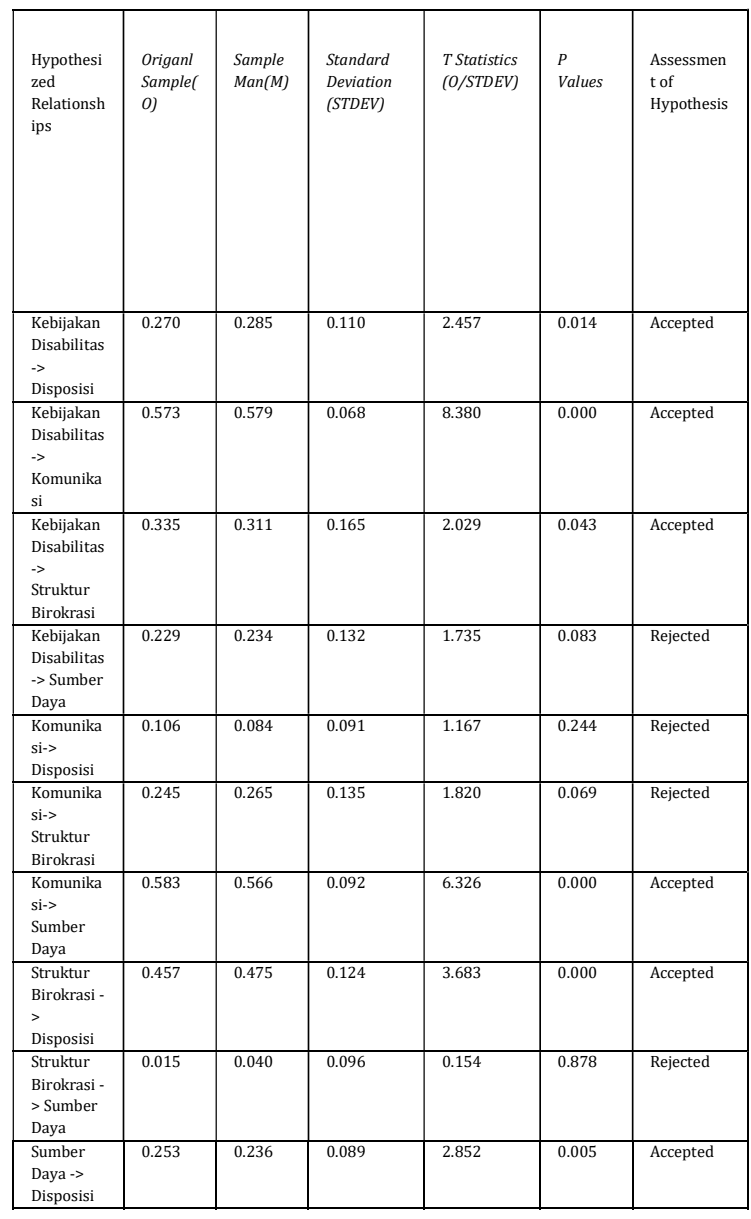

Pade tabel 9 di atas dapat diketahui bahwa variabel yang tidak memiliki pengaruh yang signifikan terhadap variable laten yaitu terdapat 4 variabel. Empat (4) hipotesa ini memiliki statistik yang lebih rendah dari kriteria pada T Statistics adalah > 1,96 (Perhatikan pada tabel 8). Kemudian, nilai P Values yang terdapat pada kelima varibel/hipotesa tersebut memiliki nilai lebih tinggi dari kriteria standard $\mathrm{P}$ Values adalah<0,05 (Haryono,2017). 


\section{Pembahasan Hipotesa Antar Variabel dalam Pemenuhan Hak-Hak Penyandang Disabilitas Berupa Jaminan Sosial di Kabupaten Gunungkidul Tahun 2018}

1) Hubungan Kebijakan Disabilitas Terhadap Disposisi, Komunikasi, Struktur Birokrasi, Sumberdaya dalam Pemenuhan Hak-Hak Penyandang Disabilitas

Berdasarkan gambar 1 dan tabel 9 di atas, maka pengujian untuk hubungan variabel Kebijakan Disabilitas dengan Disposisi, Komunikasi, Struktur Birokrasi, Sumberdaya dalam Pemenuhan HakHak Penyandang Disabilitas terdapat tiga yang berpengaruh signifikan yaitu Kebijakan Disabilitas-Disposisi, Kebijakan Disabilitas-Komunikasi, Kebijakan Disabilitas-Struktur Organisasi. Yang mana tiga variabel yang berpengaruh signifikan tersebut mempunyai nilai setatistik yang lebih tinggi dari kriteria pada $\mathrm{T}$ Statistics adalah $>1,96$ dan memiliki nilai lebih rendah dari kriteria standard $P$ Value adalah >0.05. Sedangkan Kebijakan Disabilitas-Sumberdaya tidak memiliki pengaruh signifikan, ini dikarenakan memiliki setastistik yang lebih rendah dari kriteria pada $\mathrm{T}$ Statistics adalah >1.96. Kemudian, nilai $\mathrm{P}$ Values memiliki nilai lebih tinggi dari kriteria standard $\mathrm{P}$ Values adalah $>0.05$.

\section{2) Hubungan Komunikasi Terhadap} Disposisi, Struktur Birokrasi, Sumberdaya dalam Pemenuhan Hak-Hak Penyandang Disabilitas

Berdasarkan gambar 1 dan tabel

9 di atas, maka pengujian untuk hubungan variabel Komunikasi dengan Disposisi, Struktur Birokrasi, Sumberdaya dalam Pemenuhan HakHak Penyandang Disabilitas hanya ada satu variabel yang memiliki pengaruh signifikan yaitu Komunikasi-Sumberdaya.

Komunikasi-Sumberdaya mempunyai nilai setatistik yang lebih tinggi dari kriteria pada T Statistics adalah $>1,96$ dan memiliki nilai lebih rendah dari kriteria standard $P$ Value adalah $>0.05$. Sedangkan KomunikasiDisposisi dan Komunikasi-Struktur Birokrasi tidak memiliki pengaruh signifikan, ini dikarenakan memiliki setastistik yang lebih rendah dari kriteria pada T Statistics adalah $>1.96$. Kemudian, nilai $\mathrm{P}$ Values memiliki nilai lebih tinggi dari kriteria standard $\mathrm{P}$ Values adalah $>0.05$.

\section{3) Hubungan Struktur Birokrasi Terhadap Disposis dan Sumberdaya}

Berdasarkan gambar 1 dan tabel 9 di atas, maka pengujian untuk hubungan variabel Struktur Birokrasi Terhadap Disposisi dan Sumberdaya dalam Pemenuhan Hak-Hak Penyandang Disabilitas hanya ada satu variabel yang memiliki pengaruh signifikan yaitu Struktur BirokrasiDisposisi. Struktur Birokrasi-Disposisi mempunyai nilai setatistik yang lebih tinggi dari kriteria pada $\mathrm{T}$ Statistics adalah $>1,96$ dan memiliki nilai lebih rendah dari kriteria standard $P$ Value adalah >0.05. Sedangkan Struktur Birokrasi-Sumberdaya tidak memiliki pengaruh signifikan, ini dikarenakan memiliki setastistik yang lebih rendah dari kriteria pada T Statistics adalah $>1.96$. Kemudian, nilai $\mathrm{P}$ Values 
memiliki nilai lebih tinggi dari kriteria standard P Values adalah $>0.05$.

\section{4) Hubungan Sumberdaya Terhadap Disposisi}

Berdasarkan gambar 1 dan tabel 9 di atas, maka pengujian untuk hubungan variabel SumberdayaDisposisi dalam Pemenuhan Hak-Hak Penyandang Disabilitas menunjukan pengaruh yang signifikan. Ini dikarenakan mempunyai nilai setatistik yang lebih tinggi dari kriteria pada T Statistics adalah $>1,96$ dan memiliki nilai lebih rendah dari kriteria standard $\mathrm{P}$ Value adalah $>0.05$.

\section{Pengujian Hipotesis: Independent dan Dependent}

\section{1) Hubungan yang signifikan antara Kebijakan Disabilitas-Disposisi, Kebijakan Disabilitas-Komunikasi dan Kebijakan Disabilitas- Struktur Birokrasi}

Analisis yang terdapat pada tabel 7 dan 9 serta seperti yang ditunjukkan pada gambar 1 mengungkapkan bahwa Kebijakan Disabilitas yang terdapat di Kabupaten Gunungkidul ini signifikan secara statistik dengan disposisi, komunikasi dan struktur birokrasi di jaringan. Sebagaimana dibahas, kebijakan publik di jaringan dianggap baik oleh pemerintah daerah maupun masyarakat penyandang disabilitas (lihat tabel 9).

Data menunjukan bahwa kebijakan disabilitas memiliki hubungan yang signifikan dengan disposisi, yang mengacu pada altruisme dan keinginan pemerintah daerah untuk meningkatkan pelayanan terhadap penyandang disabilitas. Bahwa ada kebijakan yang di tingkat daerah dan ada kebijakan yang berada di tingkat pusat. Keberadaan pertama yaitu lembaga sosial yang mengurusi sosial dinas sosial di daerah banyak menangkap kegiatan-kegiatan, urusan-urusan program yang sudah dikeluarkan oleh kementrian sosial termasuk didalamnya jaminan bagi penyandang disabilitas. kemudian ada regulasiregulasi yang berkaitan tentang itu, daerah juga punya regulasi, tentunya turunan dari pusat. Dinsos Membuat skala prioritas, mana yang harus di prioritaskan dulu. Ada disuatu daerah yang membutuhkan alat bantu dengar, nah kita dekati daerah tersebut dan akan diberikan bantuan. Tetapi di daerah lain memiliki kebutuhan yang lain, maka kita memberikan bantuan yang di butuhkan juga.

Selain itu, hubungan yang signifikan antara kebijakan disabilitas dan komunikasi, ada beberapa forum yang diselenggarakan oleh pusat, atau pusat melakukan kunjungan ke daerah, atau pusat mengundang beberapa daerah di suatu daerah, kita di undang. Mereka komunikasi di mediasi oleh Dinas Sosial DIY sebagai respresentasi perwakilan daerah dan Dinsos Kab Gunugnkidul aktif berkomunisasi dengan kementrian langsung yang sifatnya konsultatif. Dilakukan sosialisasi terlebih dahulu tentang jamkesus ini, kemudian ada pendamping disabilitas dari DIY untuk mendata jumlah penyandang disabilitas yang akan menerima jamkesos. Selebihnya masyarakat mendatangi Dinsos untuk pengajuan jamkesus. Kemudian pemegang kartu 
jamkesos untuk akses alat bantu dan perawatan, trlebih dhulu minta rujukan dri puskesmas/ rumah sakit kemudian rujukan dan kartu jamkesus di bawa ke bapel jamkesus, terus bapel menverifikasi berkas, keadaan pasien dan kebutuhan pasien, kemudian di kasi surat eligibilitas peserta (SEP) dari bapel untuk akses alat bantu dan perawatan ke puskesmas atau RS yang di tuju untuk mendapatkan fasilitas pelayanan kesehatan yang diinginkan tahun 2018 kebnyakan kita sistem komunitas, jadi komunitas itu penerima PKH di kumpulkan jadi satu kemudian diundang ke balai desa atau ke tempat yang memadai, kemudian pihak bank datang dan kmudian melakukan pencairan di tempat, kan mereka pakai kartu atm atau kks (kartu keluarga sejahtera) dan untuk prosedur alat bantu dan mengakses bantuan jaminan sosial berupa jamkesus penyandang disabilitas ke puskesmas/ dokter keluarga/ jamkesus terpadu kemudian ke prosedur pelayanan penjaminan SEP dari jamkesos, kemudian RS spesialis, kemudian perlu alat bantu berupa apa yang diperlukan kemudian SEP dari jamkesos dan penyediaan alat bantu bisa disalurkan serta FKDG sebagai perantara antara masyarakat penyandang disabilitas dan pemerintah daerah. Makanya tugas FKDG termasuk memberikan himbawan-himbawan untuk penyandang disabilitas yang berada di desa supaya membentuk kelompok, agar bisa terlibat dalam forum perencanaan program musren.

Kemudian hubungan yang signifikan antara kebijakan disabilitas dan struktur birokrasi bahwa pada pelayanan untuk pemenuhan hak-hak penyandang disabilitas sesuai dengan SOP dan dalam pengurusan untuk memperoleh bantuan jaminan sosial tidak terlalu panjang yang mana dalam wawancara dengan pak agus Bapel Jamkesos DIY untuk mendapatkan bantuan masyarakat penyandang disabilitas yang sudah terdaftar dan memiliki kartu jamkesus bisa langsung mengakses ke Bapel Jamkesos DIY atau melalui Dinas Sosial Kab Gunungkidul. Sedangkan untuk bantuan dari Progam Keluarga Harapan (PKH) hanya melalui Dinas Sosial ke Operator PKH dan akan di laksanakan pelayanan ke masingmasing pendamping $\mathrm{PKH}$ yang ada di setiap Kecamatan di Kabupaten Gunungkidul.

\section{2) Komunikasi dan Sumber Daya}

Pada tabel 9 menunjukan bawa komunikasi memiliki hubungan signifikan dengan sumberdaya. Secara umum komunikasi yang terjadi untuk menciptakan terwujudnya kesejahteraan dalam pemenuhan hak bagi penyandang disabilitas di Kabupaten Gunungkidul harus efektif dalam mengekstraksi sumber daya yang diperlukan untuk memastikan bahwa pemerintah daerah mampu mengimplementasikan kebijakan dalam pemenuhan hak penyandang disabilitas di bidang jaminan sosial dan sumber daya keuangan (anggaran), sesuai tupoksi serta konsisten memberikan fasilitas pelayanan. Ada beberapa kendala yang dihadapi dalam mengimplementasikan kebijakan dalam pemenuhan hak penyandang disabilitas di Kabupaten Gunungkidul. 
DOI: $10.34010 /$ agregasi.v8i1.2598

Available online at: https://ojs.unikom.ac.id/index.php/agregasi

Pertama ada alokasi program kegiatan yang kearah jaminan untuk penyandang disabilitas. hanya, yang di danai oleh daerah itu baru berkisar pada bantuan alat bantu bagi disabilitas, meskipun tidak begitu besar dari jumlah populasi penyandang disabilitas. Yang kedua, yaitu permintaan dari masyarakat penyandang disabilitas, yang mana membutuhkan pelatihan untuk bagaimana memperbaiki kursi roda yang mana terdapat problem, jika sudah di pakai, mereka tidak bisa memperbaiki jika terjadi kerusakan. Dari melaksanakan pemenuhan atas permintaan. Secara keseluruhan dalam pemenuhan hak-hak penyandang disabilitas di kab gunungkidul belum bisa terpenuhi semua. Terdapat kendala terjadinya, yaitu dana (anggaran) dan sisi SDM, dalam artian jumlah SDM di Dinsos yang kurang dengan jumlah SDM yang sangat terbatas ini, kemungkinan tidak mampu juga melakukan kegiatan-kegiatan di luar kapasaitas Dinsos, dalam artian manajemen waktunya agak kesusahan karena keterbatasan jumlah personel. Jumlah SDM di Dinsos Kab Gunungkidul yaitu 22 orang dan yang di harus di penuhi bukan permasalahan disabilitas saja, tetapi lansia, anak jalanan, sarana prasarana dll.

Karena beban kerja tinggi, SDM yang IT kurang karena kita main di data. Terkadang juga ada masyarakat yang tidak memiliki KTP, otomatis dia tidak bisa mendapatkan fasilitas, makanya kita juga minta perangkat desa untuk mengurusi hal tersebut. Untuk anggaran khusus untuk pelayanan jamkesos belum mengurusi sendiri, Dinsos Gunungkidul masih mekerja sama dengan Bapel, penyandang disabilitas kategori kaya, hanya penyandang disabilitas yg mendapakan jamkesus, jika miskin makan 1 keluarga akan mendapatkan jamkesus.

\section{3) Struktur Birokrasi dan Disposisi}

Hubungan yang signifikan Struktur Birokrasi dan Disposisi terlihat pada tabel 9 bahwa pemerintah daerah sudah mengimplementasikan kebijakan dalam pemenuhan hak-hak penyandang disabilitas sesuai dengan SOP sebagaimana dalam pelaksanaan pelayanan pemerintah daerah sudah melaksanakan, mengoptimalkan pelayanan jaminan sosial untuk penyandang disabilitas. pemerintah daerah sudah tepat sasaran dalam memberikan pelayanan dan kebijakan, yang mana mengacu pada apa yang mereka terima oleh masyarakat, keluhan, seta apa yang dibutuhkan masyarakat, maka hal itu lah yang akan di jadikan sebagai kebijakan dalam pemenuhan hak-hak penyandang disabilitas berupa jaminan sosial. Namun terdapat kendala Untuk organisasi perangat daerah di Kabupaten Gunungkidu masih taraf penyesuaian juga, jadi masih berkomunikasi untuk supaya memberikan usulan usulan program contoh akses disabilitas seperti tempat yang ramah disabilitas. FKDG memang kerjanya memberikan kritikan untuk pemerintah agar penyandang disabilitas lebih di perhatikan. Dan untuk programprogram yang belum merata belum semua organisasi perangat daerah memberikan program ke FKDG. 


\section{4) Sumber Daya dan Disposisi}

Hubungan yang signiikan antara Sumber daya dan Disposisi terdapat pada tabel 9 menunjukan pentingnya suatu mekanisme yang efektif dalam mengimplementasikan sebuath kebijakan dalam pemenuhan hak penyandang disabilitas berupa jaminan sosial. Sebagaimana sumber daya yang ada harus dimaksimalkan dengan disposisi. Dalam implementasi kebijakan pemenuhan hak penyandang disabilitas berupa jaminan sosial dalam pelaksanaannya masih banyak kekurangan, terutama miss untuk masalah pendataan yang mendapatkan bantuan jamkesus maupun PKH. Namun terlepas dari itu bahwa Bapel Jamkesos DIY dan Dinsos Gunungkidul sudah bekerja sama semaksimal mungkin untuk mensejahterakan masyarakat penyandang disabilitas, sudah berusaha untuk memenuhi semua hak penyandng disabilitas melalui program-program yang tujuannya mensejahterakan. Dengan hal ini kekurangan SDM maupun SDA, kita tetap pada komitmen untuk mensejahterakan dan memenuhi hak penyandang disabilitas.

\section{SIMPULAN DAN SARAN}

\section{Simpulan}

Hypotheses Testing: Summary of the Path Anlysis Evaluation yang terdapat pada tabel 9 dan juga hasil wawancara yang dilaksanakan di beberapa instansi terkait dalam pengimplementasian kebijakan pemenuhan hak penyandang disabilitas berupa jaminan sosial bahwa untuk pelaksanaan kebijakan dalam pemenuhan hak penyandang disabilitas terhadap disposisi atau karakteristik dan prilaku pemberi jasa layanan, dan komunikasi yang terjalin antar instansi dan penerima jasa (penyandang disabilitas) mengenai bantuan jaminan sosial, serta struktur birokrasi yang tidak panjang atau terfragmentasi dan juga sesuai SOP sudah berhasil dilaksanakan dan penerima jasa atau masyarakat penyandang disabilitas yang mendapatkan bantuan jaminan sosial merasa puas dengan hal tersebut. Begitu pula untuk komunikasi terhadap sumber daya, struktur birokrasi dengan disposisi dan sumber daya terhadap disposisi pada bagian ini pemberi jasa maupun penerima jasa mersa puas dan sudah memenuhi hak-hak penyandang disabilitas.

Namun, pada pengimplementasian kebijakan dalam pemenuhan hak-hak penyandang disabilitas berupa jaminan sosial terdapat kendala berupa sumber daya yang tidak memadai, kekurangan sumberaya sebagai ahli IT maupun SDM yang melaksanakan pemenuhan hak penyandang disabilitas dikarenakan Dinsos tidak hanya memiliki tugas untuk mensejahterakan masyarakat penyandang disabilitas, namun lansia, anak jalanan, rehabilitas dll. Selain itu, komunikasi terhadap disposisi dan struktur birokrasi masi mengalami kendala dikarenakan jarak tempuh yang jauh antar instansi dan masyarakat serta kadang kala terjadi miss komunikasi antar instansi dalam memberikan 
JURNAL AGREGASI

Jurnal Aksi Reformasi Government Dalam

Demokrasi

Volume 8- Nomor 1, Mei 2020

DOI: $10.34010 /$ agregasi.v8i1.2598

Available online at: https://ojs.unikom.ac.id/index.php/agregasi

pelayanan terutama soal pendataan jumlah masyarakat penyandang disabilitas yang layak mendapatkan bantuan jaminan sosial. Terkahir sudah sangat jelas dengan permasalah tersebut maka untuk struktur birokrasi terhadap sumber daya pun tidak efisien dalam pelaksanaan pelayanan jaminan sosial di Kabupaten Gunungkidul.

\section{Saran}

Penelitian ini adalah penelitian yang memfokuskan pada studi tentang implementasi kebijakan dalam pemenuhan hak-hak penyandang disabilitas berupa jaminan sosial di Kabupaten Gunungkidul dan menganalisis faktor-faktor yang mempengaruhi keberhasilan. Oleh karena itu, perlu adanya keberlanjutan dari penelitian ini yang meneliti mengenai implementasi kebijakan pemenuhan hak penyandang disabilitas dalam fokus yang berbeda yang masih terkait di dalam kesejahteraan sosial menurut UU No 8 tahun 2016. Penelitian tentang implementasi ini juga diharapkan dapat mengukur dan mengevaluasi kebijakan dari pemerintah tersebut untuk mengembangkan kebijakan pemenuhan hak penyandang disabilitas di daerah masing-masing.

\section{DAFTAR PUSTAKA}

Abdillah, W. dan Hartono, J. (2015). Partial Least Square (PLS): Alternatif Structural. Equation
Modeling (SEM) dalam Penelitian Bisnis. Yogyakarta: Penerbit.

Creswell, J. W. (2010). Research design:

Pendekatan Kualitatif, Kuantitatif, dan Mixed.

Yogjakarta: PT Pustaka Pelajar.

Ghozali, Imam, Hengky Latan. (2015).

Konsep, Teknik, Aplikasi

Menggunakan Smart PLS 3.0

Untuk Penelitian Empiris. BP

Undip. Semarang.

Haryono, Siswoyo. (2017). Metode SEM

Untuk Penelitian Manajemen

Dengan AMOS LISREL PLS.

Luxima Metro Media.

Hasan, M. Iqbal. (2015). Pokok-pokok Materi Statistik 2. Jakarta: PT Bumi Aksara.

Husaini Usman. (2008). Metodologi Penelitian Sosial. Jakarta: Bumi Aksara.

Hardiansyah. (2011). Kualitas Pelayanan Publik. Yogyakarta: Gava Media.

M. Syafi'ie. (2014). Pemenuhan Aksesibilitas Bagi Penyandang Disabilitas Peneliti pada LSM Sigap Yogyakarta Vol.1, No. 2

Noor, Juliansyah. (2011). Metodologi Penelitian. Jakarta: Kencana Prenada Kencana Group.

Nursalam. (2013). Metodologi Penelitian Ilmu Keperawatan: Pendekatan Praktis. Jakarta: Selemba Medika. 
DOI: $10.34010 /$ agregasi.v8i1.2598

Available online at: https://ojs.unikom.ac.id/index.php/agregasi

Peraturan Bupati Kabupaten

Gunungkidul Nomor 9 Tahun 2016 Tentang Penyelenggaraan Perlindungan Dan Pemenuhan Hak Penyandang Disabilitas.

Peraturan Daerah (PERDA) Kabupaten Gunungkidul Nomor 9 Tahun 2016 Tentang Penyelenggaraan Perlindungan dan Pemenuhan Hak Penyandang Disabilitas.

Sugi Rahayu dan Utami Dewi. (2012). Pelayanan Publik Bagi Pemenuhan Hak-Hak Disabilitas Di Kota Yogyakarta, 3-5. Retrieved from https://journal.uny.ac.id/index.p hp/natapraja/article/download/ $\underline{3194 / 2676}$

Undang-Undang Nomor 19 Tahun 2011 tentang Pengesahan Convention on the Rights of Persons with
Disabilities (Konvensi Hak-hak

Penyandang Disabilitas

Undang-Undang Nomor 4 Tahun 1997 tentang Penyandang Cacat

Undang-Undang Nomor 8 Tahun 2016 Tentang Penyandang Disabilitas

Website Resmi Dinas Sosial Kabupaten Gunungkidul. Retrieved from http://gunungkidulkab.go.id/

Wirawan. (2011). Evaluasi Teori Model Standar Aplikasi dan Profesi, Contoh Aplikasi Evaluasi Program: Pengembangan Sumber Daya Manusia, Program Nasional Pemberdayaan Masyarakat (PNPM) Mandiri Pedesaan, Kurikulum, Perpustakaan, dan Buku Tes. Jakarta: Raja Grafindo Persada. 